\title{
Preparation of Chitosan Nanoparticles and its Utilization as Novel Powerful Enhancer for Both Dyeing Properties and Antimicrobial Activity of Cotton Fabrics
}

\author{
Tawfik M. Tawfik ${ }^{1, *(\mathbb{D})}$, Ahmed M. A. El-Masry ${ }^{2}$ (D) \\ 1 Faculty of Applied Arts, Textile Printing, Dyeing and Finishing Department, Benha University, Benha, Egypt; \\ tm.tawfik@aol.com (T.M.T.); \\ 2 Physics Department, Ain Shams University, Cairo, Egypt; masry747@gmail.com (A.A.M.E.M.); \\ * Correspondence: tm.tawfik@aol.com;
}

Scopus Author ID 36182463800

Received: 18.12.2020; Revised: 4.02.2021; Accepted: 7.02.2021; Published: 14.02.2021

\begin{abstract}
Replacement of conventional chemicals with modern fewer hazards one has great attention via green chemistry. Chitosan nanoparticles (CSNPs) were prepared from the reaction of chitosan $(0.2$ $\mathrm{g} / 100 \mathrm{ml})$ with tripolyphosphate $(0.1 \mathrm{~g} / 100 \mathrm{ml})$ through the ionotropic gelation method. CSNPs with different concentrations were used for cotton fabrics to impart antimicrobial activity and enhance their dyeing affinity towards acid dyes. FT-IR spectroscopy and TEM imaging were used to characterized CSNPs. SEM and TGA. Effect of CSNPs concentrations on cotton fabric dyeing affinity was recorded from colorimetric data. The antimicrobial activity of treated dyed fabrics was evaluated via disk diffusion method against S. aureus, E. coli, Candida, and Aspergillus Niger. Results have shown that cotton fabrics treated with $0.3 \mathrm{~g} / 100 \mathrm{ml}$ record the highest K/S values, Corresponding to the highest dyeing affinity towards acid dyes. In addition, treated dyed cotton fabrics were showed higher antimicrobial activity towards tested microorganisms because of the presence of CSNPs. Morphological studies on the untreated, treated, and treated dyed cotton fabrics via SEM imaging confirmed that CSNPs coated cotton fabrics. In addition, the light and washing fastness properties of these fabrics confirmed their durability. Therefore, CSNPs were used to impart cotton fabrics' antibacterial activity and improve their dyeability with acid dye.
\end{abstract}

Keywords: chitosan nanoparticles; cotton fabrics; acid dyes; dyeing and antimicrobial.

(c) 2021 by the authors. This article is an open-access article distributed under the terms and conditions of the Creative Commons Attribution (CC BY) license (https://creativecommons.org/licenses/by/4.0/).

\section{Introduction}

Cotton fabrics have been widely used in the textiles industry because of their high contents of cellulose, up to $96 \%$ according to the fibers' weight [1,2]. The physical and chemical properties of cotton fabrics were excellent from their stability, water absorptivity, comfortability, and high affinity towards dyes. Cotton fabrics had high affinity to reactive dyes, but it has no affinity towards acid dyes $[3,4]$ due to its chemical structure which has not any basic functional groups. Amination of cotton fabrics has a major back draw from its lower degree of substitution, and it causes depolymerization for cotton chains. Therefore, finishing cotton fabrics with chitosan has great attention to improving its dyeability and imparting it good antibacterial activity [5,6].

Today acid and direct dyes are widely used for cotton fabrics due to the presence of hydroxyl groups [7,8], but the main back draw is cotton fabrics have not any affinity to acid dyes so that cationic groups were needed to improve the dyeability of cotton fabrics with acid https://biointerfaceresearch.com/ 
dyes by using cationized materials for these fabrics $[1,9,10]$. Although these cationized agents have several advantages for the acid dyeability of cotton fabrics, we can believe that the chemical process did not agree with environmental aspects regulations because of their toxic effects during chemical processes [2,11,12]. Surface modification of cotton fabrics using biopolymers such as chitin, chitosan, or gelatin in their finishing processes could offer the best solution to avoid these risks [4,13-15].

Chitosan is a natural cationic polymer of $\beta-1,4$ glucose amine, and $\beta-1,4-\mathrm{N}$-acetyl glucose amine units [16-18]. It is biocompatible, biodegradable, and non-toxic. It has great power for biomedical applications e.g., protein carrier, drug delivery, and wound healing [1,16,19-26]. Chitosan nanoparticles (CSNPs) have a large surface area, zeta potential, and provides superior activity [26-28]. CSNPs have many applications in biomedical fields and are used as poly load agents in the delivery of drugs [29-31], vaccine [32-34], and gene [35-38]. Chitosan nanoparticles exhibit higher antibacterial activity than chitosan-based on the nanoparticles' special character [39-41]. Chitosan nanoparticle is a drug carrier with some advantage of slow and controlled drug release, which improves drug solubility and stability, efficacy, and reduces toxicity [24,25,42-45]. Several methods have been developed to prepare chitosan nanoparticles, such as emulsion crosslinking, emulsion droplet coalescence, precipitation, ionotropic gelation, reverse micelle, template polymerization and molecular selfassembly $[45,46]$. Several factors are required to select the preparation method, such as particle size, thermal and chemical stability, and stability and of the final product [47-49]. Textile applications of chitosan can be classified into two main categories: human-made fibers production and fibers wet processing, which includes enhancement of both finishing, dyeing, and printing processes [50]. Until now, most applications of chitosan in textile industries is considered as an antibacterial agent, but few applications deal about its role as improvements of dye ability, so that our main aim of this study to illustrate the role of chitosan to enhance dye ability of cotton fabrics with acid dye as well as its antibacterial properties compared with untreated dyed cotton fabrics [11,16,51]. Acid dyes were commonly used for wool and silk fabrics and rare for cotton fabrics due to cotton fabrics' anionic nature. However, acid dyes have a low affinity towards cotton fabrics. Adding cationic groups from quaternary ammonium slats were solve these problems, but it makes toxicity risks during and after dyeing processes due to these are not safe materials. Therefore, using chitosan as a polycationic biopolymer can solve this problem without and risks to produce more safe, eco-friendly materials.

The present paper deals with enhancing dyeing properties and antimicrobial activity of cotton fabrics pretreated with the prepared natural biopolymer chitosan nanoparticles to have a high affinity of dyeing towards acid dyes. Then, other textile properties such as the physical and antimicrobial activity of the nano chitosan-finished cotton fabrics were studied.

\section{Materials and Methods}

\subsection{Materials.}

Cotton fabrics 100\% were used. Chitosan (Alfa Aesar Company, Medium molecular weight, viscosity $1860 \mathrm{cps}$, degree of deacetylation 79.0\%), Penta sodium tri poly phosphate (TPP). Sodium hydroxide (Modern Lab chemicals, Egypt), Astroglitter binder® based on nonionic/anionic acrylic resin compound, citric acid, sodium hypophosphite, and Hostapal ${ }^{\circledR}$ CVLET (non-ionic wetting agent based on alkyl aryl polyglycol ether, Clariant), and all other chemicals used are analytical grade and were used without further purification. Two acid dye ${ }^{\circledR}$ 
were used acid orange 7 and acid red 88., single azo, Ohyoung Industrial Co., Ltd. The structural formulas of dye are shown in Scheme 1.<smiles>O=S(=O)(O[Na])c1ccc(/N=N/c2c(O)ccc3ccccc23)cc1</smiles>

7 (AO dye)<smiles>O=S(=O)(O[Na])c1ccc(/N=N/c2c(O)ccc3ccccc23)c2ccccc12</smiles>

Acid red 88 (AR dye)

Scheme 1. Chemical structure of two commercial acid dyes used; acid orange 7 (left) and acid red 88 (right).

2.2. Methods.

2.2.1. Preparation of chitosan nanoparticles (CSNPs).

Chitosan nanoparticles were prepared based on the modified ionotropic gelation method [41].

2.2.2. Finishing of Fabrics with chitosan nanoparticles.

Cotton fabrics were treated with chitosan nanoparticles by the pad-dry-cure method [27].

\subsubsection{Fabric Dyeing Procedures with acid dyes.}

The treated and untreated cotton fabrics were dyed with acid dyes by a common process. Where, a solution containing $5 \mathrm{wt} . \%$ dye (o. w. f) and acetic acid with a concentration $5 \mathrm{wt} . \%$ were used. The dyeing process started at $40{ }^{\circ} \mathrm{C}$ and raised to $100{ }^{\circ} \mathrm{C}$ for $30 \mathrm{~min}$, and the dyeing was performed at $100{ }^{\circ} \mathrm{C}$ for $40-60 \mathrm{~min}$ using material-to-liquor ratio 1:50. After dyeing, the fabrics were thoroughly washed with $1-5 \mathrm{~g} / \mathrm{L}$ of non-ionic detergent for $30 \mathrm{~min}$ at $60{ }^{\circ} \mathrm{C}$ and then washed with cold water. The dyed fabrics were dried (Scheme 2).

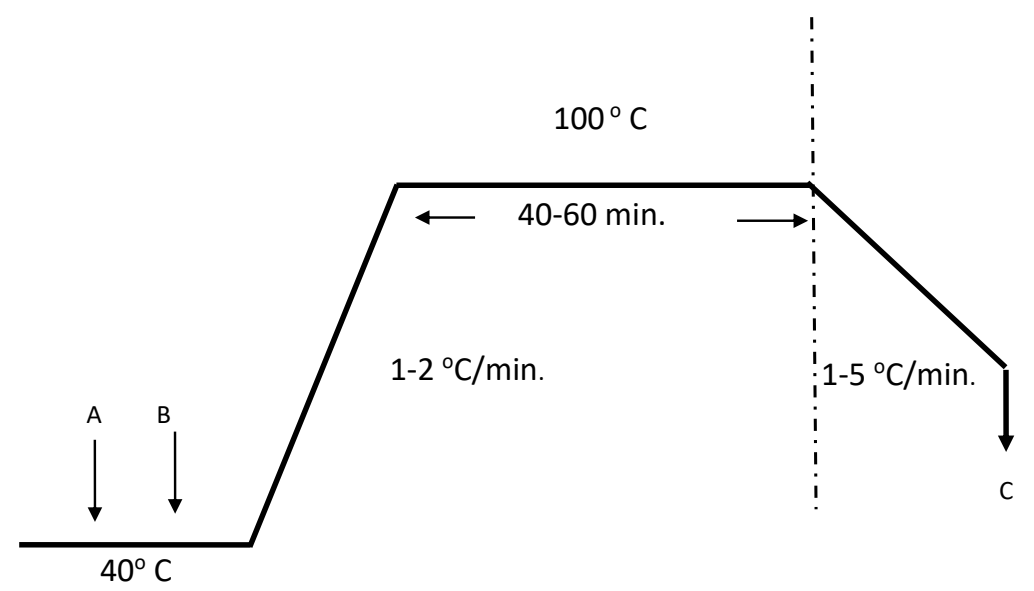

A: Levelling agent; 0.5-2.0\%, PH with Buffer or PH sliding system, B: Dye \& C: Drain and Rinse.

Scheme 2. Processing Dyeing curve of the two commercial acid dyes used.

2.4. Testing and analysis.

2.4.1. FT-IR spectra.

The FT-IR spectra of the samples were recorded by using an FT- IR spectrophotometer (JASCO FT-IR-6100). 
2.4.2. Transmission electron microscopy (TEM).

The shape and size of chitosan nanoparticles and their loaded antibiotics were investigated by using TEM; JEOL-JEM-1200.

2.4.3. Scanning electron microscopy (SEM).

Microscopic investigations on fabric samples were carried out using a Philips XL30 scanning electron microscope (SEM) equipped with a LaB6 electron gun and a PhilipsEDAX/DX4.

2.4.4. Thermogravimetric analysis (TGA).

Thermogravimetric analysis (TGA) was performed using the instrument: SDT Q600 V20.9 Build 20, USA.

2.4.5. Fastness properties.

\subsubsection{Washing fastness.}

The color fastness to washing was determined according to ISO 105- $\mathrm{CO}_{2}: 1989$ test method. The washing fastness tests were conducted in a launder meter (ATLAS-Germany) using $5 \mathrm{~g} / \mathrm{L}$ non-ionic detergent at $50^{\circ} \mathrm{C}$ for $45 \mathrm{~min}$.

\subsubsection{Light fastness.}

This test was evaluated according to ISO 105-B02: 1988 test method using a carbon arc lamp.

\subsubsection{Rubbing fastness.}

Rubbing fastness was determined according to test method ISO 105-X12: 1987 [52].

\subsubsection{Color measurements of the dyed fabrics.}

Colour-difference formula $\triangle \mathrm{E} \operatorname{CIE}\left(\mathrm{L}^{*}, \mathrm{a}^{*}, \mathrm{~b}^{*}\right)$ : The total difference $\triangle \mathrm{E}$ CIE $\left(\mathrm{L}^{*}, \mathrm{a}^{*}\right.$, $b^{*}$ ) was measured using the Hunter-Lab spectrophotometer (model: Hunter Lab DP-9000). The color strength can be calculated as follow:

$$
\text { Relative colour strength }=\frac{K / S \text { oftretaedsamples }}{K / S \text { of untreated samples }} \times 100
$$

\subsection{Evaluation of antibacterial activity in vitro.}

\subsubsection{Materials.}

Four bacterial strains were Staphylococcus aureus (S. aureus, ATCC 6538) and Bacillus subtilis (B. subtilis, ATCC 6633) as Gram-positive bacteria and Escherichia coli (E. coli, ATCC 11229) and Proteus (ATCC 33420) as Gram-negative bacteria. Antifungal activity was carried out against (Aspergillus Niger, ATCC 13497)) and (Candida, ATCC 10231). Ciprofloxacin was used as a standard drug. 


\subsubsection{Test method.}

The antibacterial and antifungal activities of treated and dyed samples were evaluated using the disk diffusion method on an agar plate [5,53].

\section{Results and Discussion}

\subsection{Preparation of chitosan nanoparticles.}

Chitosan nanoparticles were prepared from chitosan through the conversion of $-\mathrm{NH}_{2}$ groups of chitosan into $-\mathrm{NH}^{3+}$ [47,54-58]. Hiren, we prepared chitosan nanoparticles via ionotropic gelation of chitosan and tripolyphosphate [41]. Chitosan nanoparticles have more advantages than chitosan from their high surface area make them contains more amino groups than chitosan itself [41].

Fig. 1 shows the TEM image of the prepared chitosan nanoparticles from chitosan concentration of $0.2 \mathrm{wt} . \%$ and $0.1 \mathrm{wt} . \%$ TPP for $45 \mathrm{~min}$. Ultrasonication time and 5.5.pH value. Fig. 1 shows that CSNPs have particles size from $25-25 \mathrm{~nm}$.

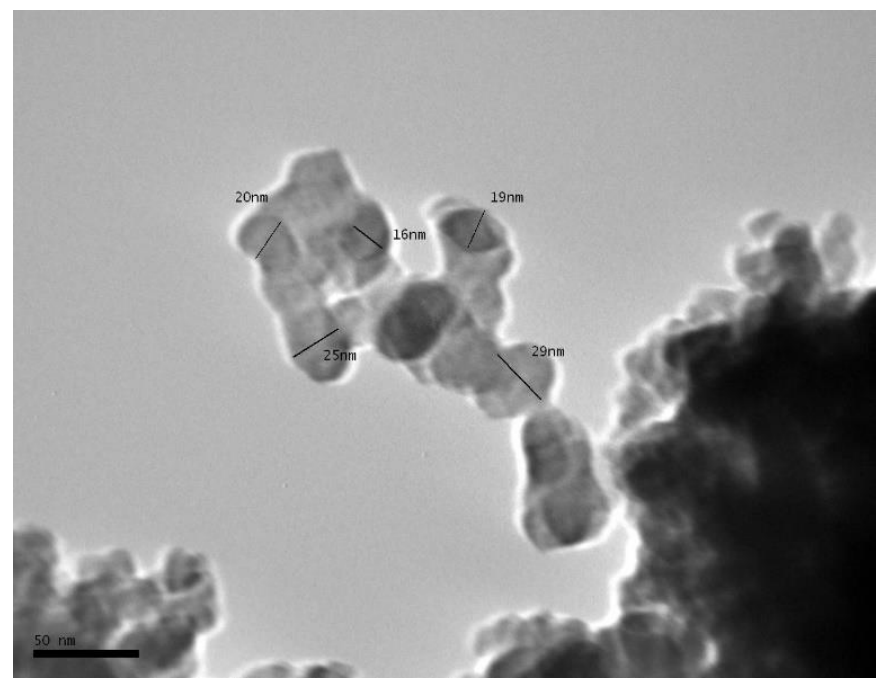

Figure 1. TEM of chitosan nanoparticles from chitosan concentration of $0.2 \mathrm{wt} . \%$ and $0.1 \mathrm{wt} \%$ TPP for $45 \mathrm{~min}$. ultrasonication time and 5.5.pH value.

Fig. 2. shows FT-IR of both chitosan (CS) and chitosan nanoparticles (CSNPs). Chitosan shows band peaks at $3434 \mathrm{~cm}^{-1}$ for amino groups and two at $1637 \mathrm{~cm}^{-1}$ and $1564 \mathrm{~cm}^{-}$ ${ }^{1}$ for amide I and amide II [40,59]. Chitosan nanoparticles have an FT-IR chart like that for chitosan with wider and shifted band peaks, as shown in Fig. 2. [27,41,45,60].

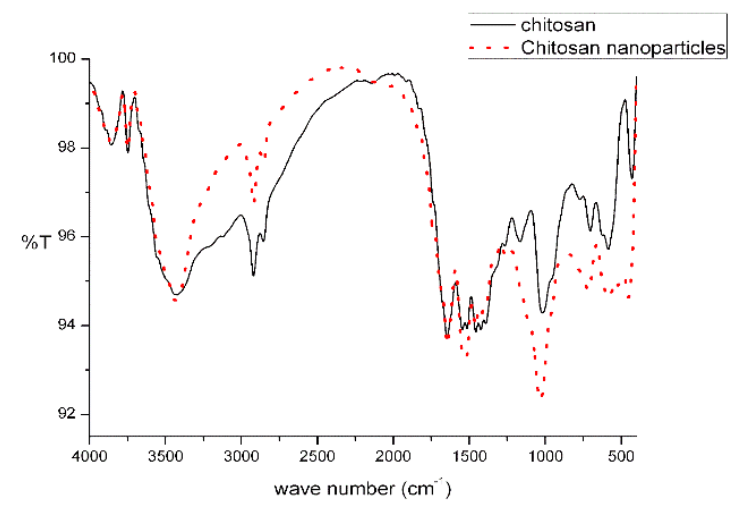

Figure 2. FT-IR spectra of (a) chitosan nanoparticles (CSNPs) and chitosan (CS). 
3.2. Finishing of cellulosic cotton fabrics with chitosan nanoparticles and its dyeing with two acid dyes.

The effect of chitosan nanoparticles on the mechanics and physics chemical properties of cotton fabrics is shown in Table 1 . There is an increase in finished cotton fabrics' nitrogen content due to the presence of CSNPs moiety within cotton fabrics that contain amino groups. The increase in nitrogen content can improve the antimicrobial activity of finished cotton fabrics. There is a slight increase in mechanical properties of finished cotton fabrics compared with untreated cotton fabrics. The unusual improvement in mechanical properties can come from great penetration of CSNPs within cotton fabrics, enhancing crosslinking between amino and hydroxyl groups of CSNPs and hydroxyl groups of cotton fabrics due to the nanostructure of CSNPs [27]. In addition, WI of finished fabric was increased, whereas YI was decreased due to the nanostructure of CSNPs.

Table 1. Mechanical and physicochemical properties of cotton fabrics, CSNPs finished cotton fabrics and its dyed and finished fabrics.

\begin{tabular}{l|c|c|c|c|c}
\multirow{2}{*}{ Sample } & \multicolumn{5}{c}{ Cotton samples with CSNPs } \\
\cline { 2 - 6 } & N $(\%)$ & E. at break & TS (kg) & YI & WI \\
\hline Cotton fabrics & 0.0 & 10 & 50 & 1.57 & 55.36 \\
\hline Cotton fabrics finished with CSNPs & 0.17 & 11 & 51 & 1.34 & 55.46 \\
\hline AO dyed cotton fabrics finished with CSNPs & 0.21 & 13 & 53 & 1.22 & 55.87 \\
\hline AR dyed cotton fabrics finished with CSNPs & 0.22 & 15 & 55 & 1.20 & 56.14
\end{tabular}

* WI: whiteness index and YI: yellowness index

Figs. 3. illustrates FT-IR spectra of untreated cotton fabric, chitosan nanoparticles (CSNPs) treated cotton fabrics, and treated and dyed cotton fabrics. The FT-IR spectra of untreated cotton fabrics show typical band peaks of $\mathrm{OH}$ and $\mathrm{CH}$ stretching groups at 3340, 2900, and band at 1648, 1428 and $1057 \mathrm{~cm}^{-1}$ for $\mathrm{OH}$ and $\mathrm{CH}$ stretching [61]. CSNPs treated cotton fabrics showed more broadband peaks due to hydrogen bonds of amino and hydroxyl groups in both nano chitosan and cellulose molecules. FT-IR spectra of treated and dyed cotton fabrics combine bands of cotton, CSNPs, and two dyes. In addition, peaks of two acid dyes appear with redshift.

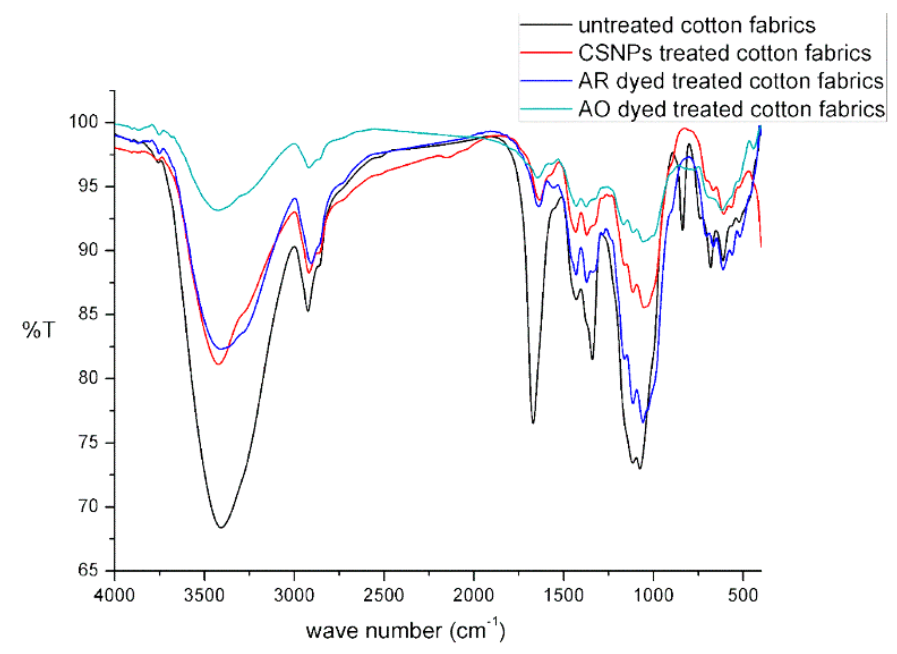

Figure 3. FT-IR Spectra of untreated and CSNPs treated and dyed cotton fabrics with AO and AR acid dyes.

TGA's thermal analysis has been used to describe the change of weight loss with gradual temperature increasing from room temperature tell complete decomposition. Fig. 4. illustrates the thermal behavior of untreated, treated, and treated dyed cotton fabrics under the 
same conditions. Fig. 4. shows three main decomposition stages of all samples but different in their position. For untreated cotton fabrics, its start decomposes below $320^{\circ} \mathrm{C}$ (volatilization of few M. wt. substances); then decomposes in 320-380 ${ }^{\circ} \mathrm{C}$ range (L-glucose production); then carbonized over $400{ }^{\circ} \mathrm{C}$. Treated cotton fabric shows the same stages with more thermal stability due to chitosan nanoparticles containing amino groups. The same improvement in thermal stability appears for dyed fabrics also dye to both amino groups of CSNPs and $\mathrm{N}=\mathrm{N}$ for acid dyes (see Fig. 4).

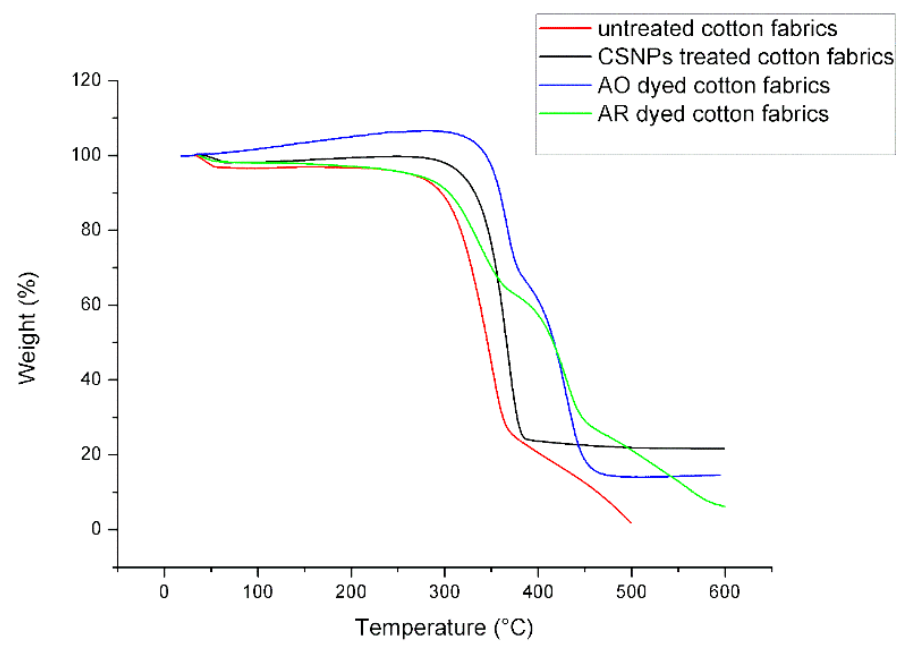

Figure 4. TGA of untreated COT sample, CSNPs treated cotton fabrics, AO and AR treated and dyed cotton fabrics.

The surface morphology of treated and dyed cotton fabrics has been investigated via scanning electron microscopy (SEM). Fig. 5 shows the change in cotton fabric morphology through treatment with chitosan nanoparticles (CSNPs) and dyeing with two acid dyes. Untreated cotton fabrics show a smooth surface (Fig. 5a). The smooth surface contains remarkable nanoparticles form CSNPs inside and outside the fiber surface (Fig. 5b). Dyeing with two acid dyes appears as coated and granulated CSNPs of the cotton fabrics (Fig. 5c and 5d). Therefore, SEM imaging confirms the presence of CSNPs inside and outside cotton fabrics for finished and finished dyed cotton fabrics and the coating process for dyed cotton samples.

\subsection{Colour strength.}

The K/S value of dyed fabrics was related directly to the amount of dye absorbed at the cotton fabrics by two acid dyes. Acid dye had higher K/S values than acid orange dye, as shown in Fig. 6. In addition, K/S values for two acid dyes were increased as chitosan's concertation increased, as shown in Fig. 6. This could be attributed to the creation of the cationic site on cotton fabrics that increased as the amount of chitosan increased on the cotton fabrics. Chitosan has three reactive groups; one amino group and two hydroxyl groups (one primary and the other is the second group), can bind with fabrics and acid dye simultaneously with and without a crosslinking agent. 


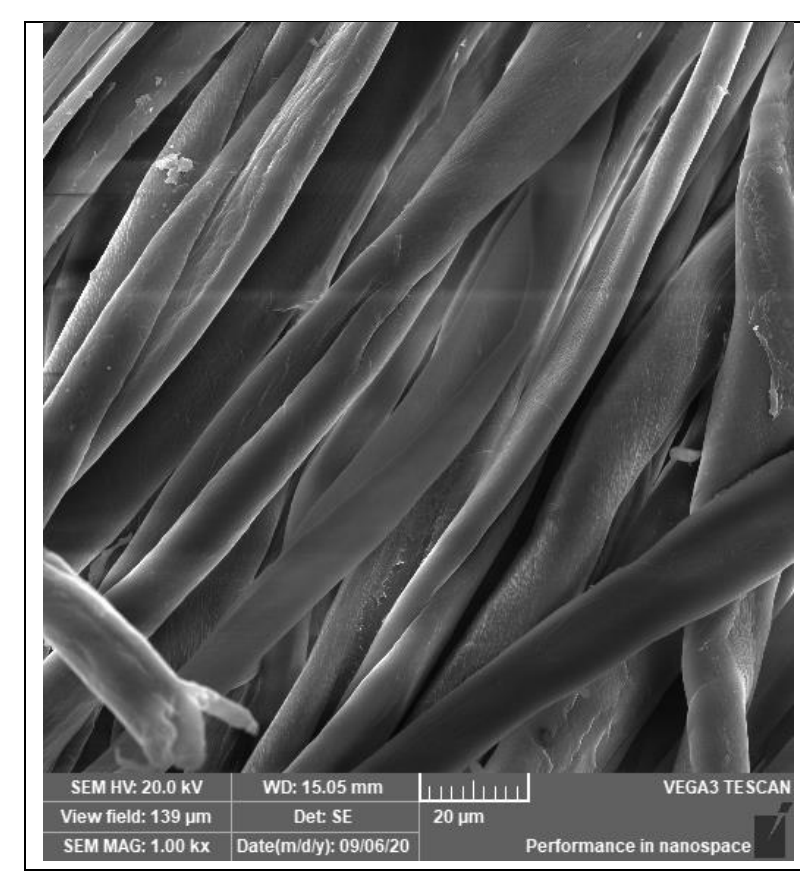

(a)

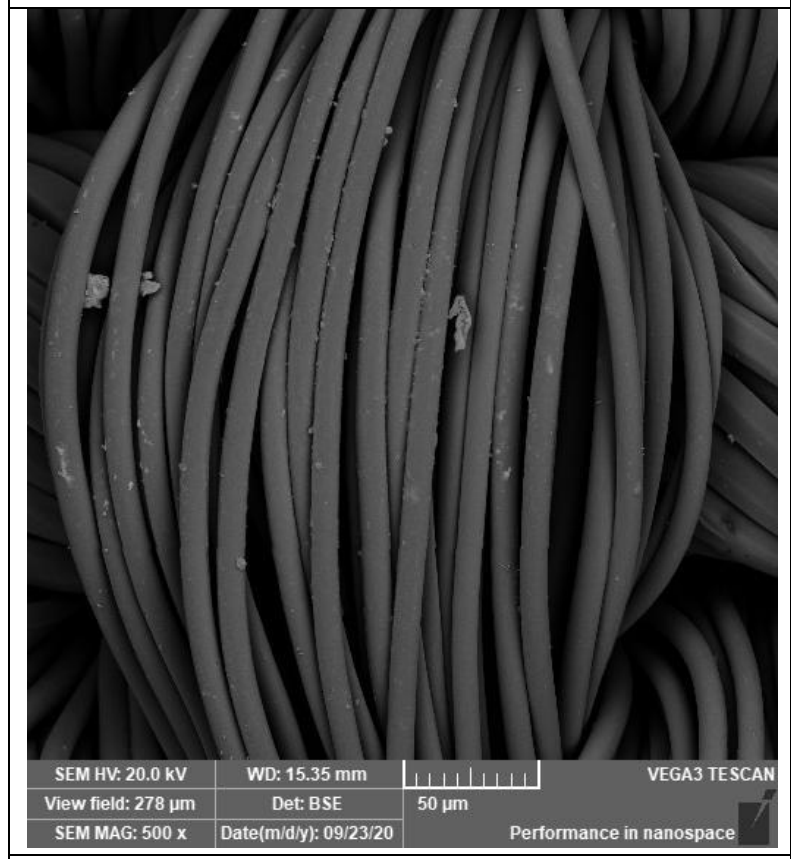

(c)

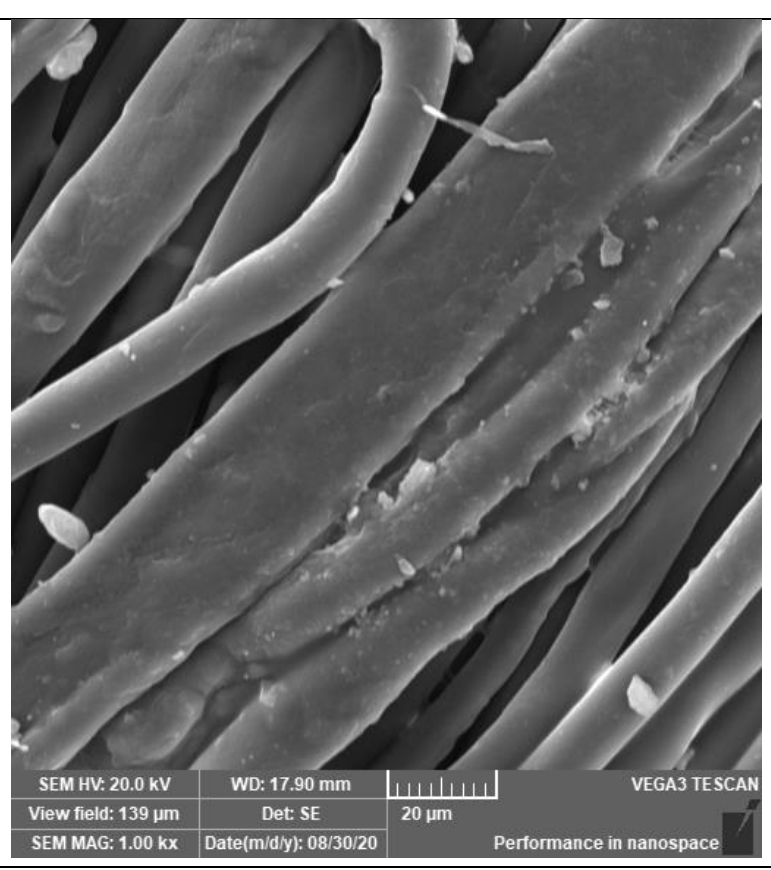

(b)

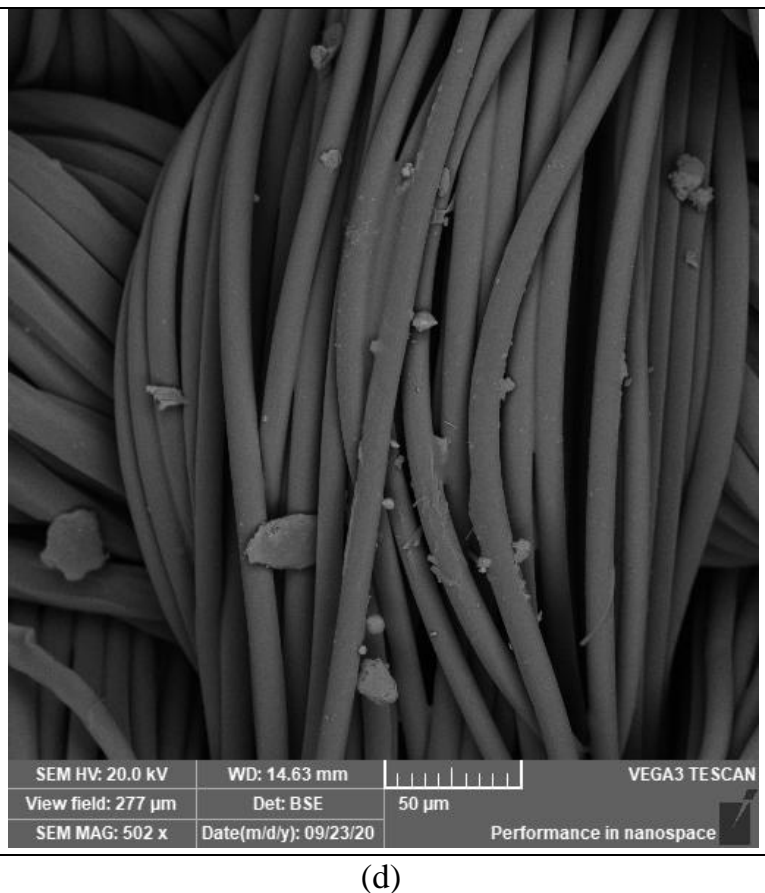

(d)

Figure 5. SEM images of untreated cotton fabric (a), CSNPs treated cotton fabric (b), AO dyed cotton fabrics finished with CSNPs (c) and AR dyed cotton fabrics finished with CSNPs (d).

Also, we can have observed that $\mathrm{K} / \mathrm{S}$ values have been increased as the chitosan concentration increased up to $0.2 \mathrm{wt} . \%$, and after that, it decreased. This concentration, the cotton fabrics became saturated with chitosan and did not need any of that for dyes. At the same time, it will be competing for the fabrics for dye absorption, which gave that decrease in $\mathrm{K} / \mathrm{S}$ values after that concentration. In addition, the energy difference shows the same trend as $\mathrm{K} / \mathrm{S}$ for chitosan concentration, which has significantly increased until 0.2 wt. \% chitosan concentration after that it will be decreased for the same reason.

\subsection{Fastness properties.}

The dyed cotton fabrics with shade $0.2 \mathrm{wt} \%$ were subjected to washing with $2 \mathrm{~g} / \mathrm{L}$ nonionic detergents at $88{ }^{\circ} \mathrm{C}$ for $0.5 \mathrm{~h}$, and light to investigate their durability towards light and 
washing. Table 1 illustrate fastness properties towards washing, rubbing, and respiration of chitosan treated cotton fabrics dyed with acid dye.

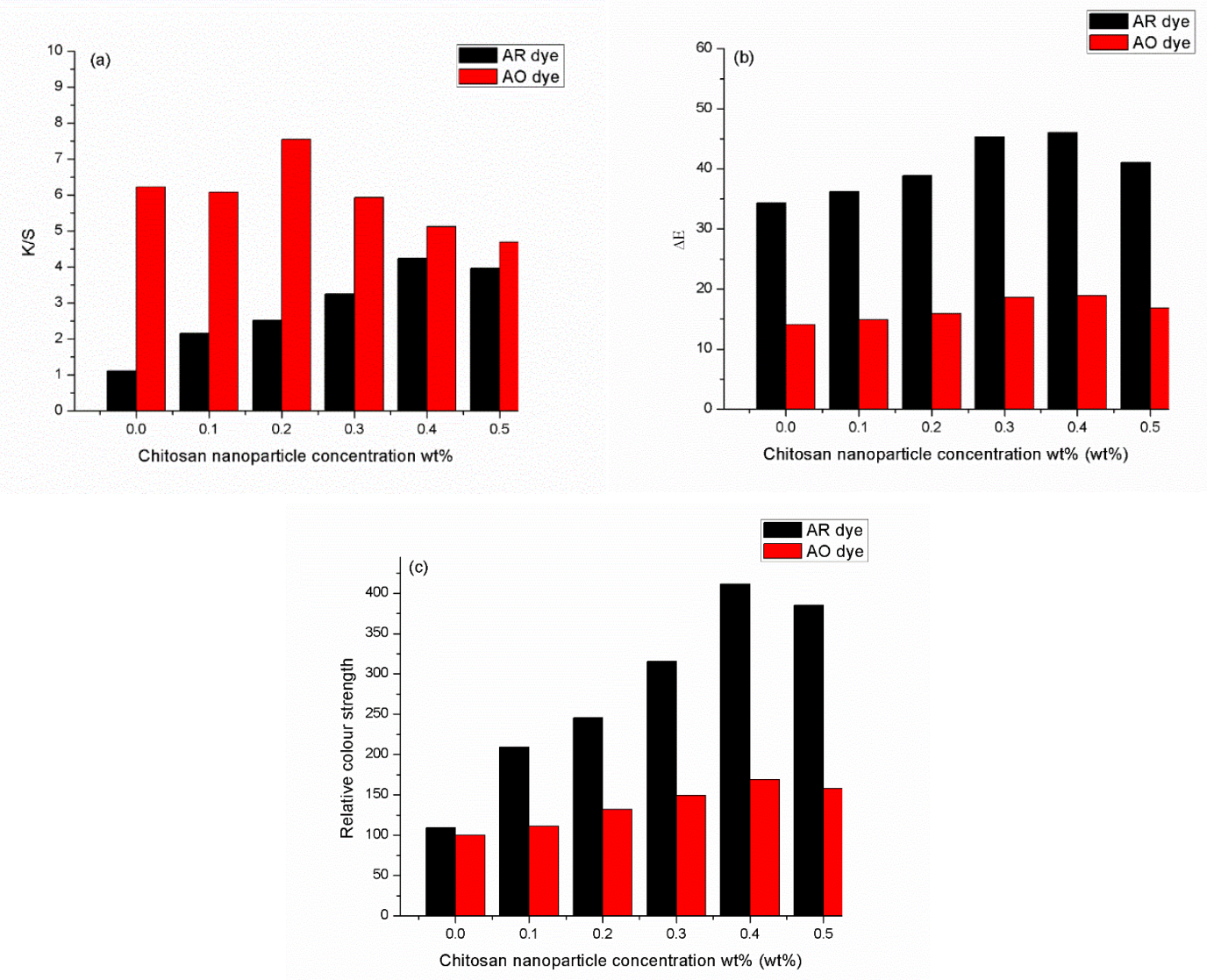

Figure 6. Effect of chitosan concentration on color strength of $\mathrm{AR}$ and $\mathrm{AO}$ acid dyes $\mathrm{K} / \mathrm{S}$ data (a); $\Delta \mathrm{E}$ values (b) and relative color strength (c).

Table 1. Fastness properties of AO and AR acid dyes on $0.2 \mathrm{wt} . \%$ chitosan nanoparticles treated cellulosic cotton fabrics.

\begin{tabular}{|c|c|c|c|c|c|c|c|c|c|c|c|c|c|}
\hline \multirow{3}{*}{\multicolumn{2}{|c|}{$\begin{array}{l}\text { Chitosan } \\
\text { nanoparticles } \\
\text { concentration } \\
(\text { wt\%) }\end{array}$}} & \multirow{2}{*}{\multicolumn{2}{|c|}{$\begin{array}{c}\text { Fastness to } \\
\text { rubbing }\end{array}$}} & \multirow{2}{*}{\multicolumn{3}{|c|}{ Wash fastness ${ }^{* *}$}} & \multicolumn{6}{|c|}{ Fastness to perspiration** } & \multirow[t]{3}{*}{ Light } \\
\hline & & & & & & & \multicolumn{3}{|c|}{ Alkaline } & \multicolumn{3}{|c|}{ Acidic } & \\
\hline & & Dry & Wet & Alt & SC & SW & Alt & $\mathrm{SC}$ & SW & Alt & $\mathrm{SC}$ & SW & \\
\hline \multirow[t]{2}{*}{0.1} & $\mathrm{AO}$ & $4-5$ & 4 & $4-5$ & $4-5$ & $4-5$ & $4-5$ & $4-5$ & $4-5$ & $4-5$ & $4-5$ & $4-5$ & \multirow[t]{2}{*}{$4-5$} \\
\hline & AR & $4-5$ & 4 & $4-5$ & $4-5$ & $4-5$ & $4-5$ & $4-5$ & $4-5$ & $4-5$ & $4-5$ & $4-5$ & \\
\hline \multirow[t]{2}{*}{0.2} & $\mathrm{AO}$ & $4-5$ & 4 & $4-5$ & $4-5$ & $4-5$ & $4-5$ & $4-5$ & $4-5$ & $4-5$ & $4-5$ & $4-5$ & \multirow[t]{2}{*}{$4-5$} \\
\hline & $\mathrm{AR}$ & $4-5$ & 4 & $4-5$ & $4-5$ & $4-5$ & $4-5$ & $4-5$ & $4-5$ & $4-5$ & $4-5$ & $4-5$ & \\
\hline \multirow[t]{2}{*}{0.3} & $\mathrm{AO}$ & $4-5$ & 4 & $4-5$ & $4-5$ & $4-5$ & 4-5 & 4-5 & 4-5 & 4-5 & $4-5$ & 4-5 & \multirow[t]{2}{*}{5} \\
\hline & AR & $4-5$ & 4 & $4-5$ & $4-5$ & $4-5$ & $4-5$ & $4-5$ & $4-5$ & $4-5$ & $4-5$ & $4-5$ & \\
\hline \multirow[t]{2}{*}{0.4} & $\mathrm{AO}$ & $4-5$ & 4 & $4-5$ & 4-5 & 4-5 & 4-5 & 4-5 & 4-5 & 4-5 & $4-5$ & 4-5 & 5 \\
\hline & AR & $4-5$ & 4 & $4-5$ & 4-5 & $4-5$ & $4-5$ & $4-5$ & $4-5$ & $4-5$ & $4-5$ & $4-5$ & \\
\hline \multirow[t]{2}{*}{0.5} & AR & $4-5$ & 4 & $4-5$ & $4-5$ & 4-5 & 4-5 & $4-5$ & $4-5$ & 4-5 & $4-5$ & 4-5 & \multirow[t]{2}{*}{$5-6$} \\
\hline & $\mathrm{AO}$ & $4-5$ & 4 & $4-5$ & $4-5$ & $4-5$ & $4-5$ & $4-5$ & $4-5$ & $4-5$ & $4-5$ & $4-5$ & \\
\hline
\end{tabular}

${ }^{*} \mathrm{C}$, Cotton; W, wool; S, silk; ${ }^{* *}$ Alt = alteration; $\mathrm{SC}=$ staining on cotton; $\mathrm{SW}=$ staining on wool

\subsection{Colour change.}

Table 2 illustrates the color change of cotton fabrics treated with different chitosan concentrations before dyeing with the two acid dyes. It could be shown that yellowness of treated cotton fabrics increased as the concentration of chitosan increased ( $b^{*}$ values), whereas there was a slight decrease in the lightness of these fabrics with chitosan concentrations increased $\left(\mathrm{L}^{*}\right)$ values. This is because amino groups of chitosan can react with hydroxyl groups 
in cotton fabrics. Therefore, the cotton fabric lusters no change with chitosan concentration increased.

Table 2. Colour change of cellulosic cotton fabrics treated with different concentrations of chitosan.

\begin{tabular}{c|c|c|c}
$\begin{array}{c}\text { Chitosan nanoparticles } \\
\text { concentration (wt\%) }\end{array}$ & $\mathbf{L}^{*}$ & $\mathbf{a}^{*}$ & $\mathbf{b}^{*}$ \\
\hline 0 & 85.16 & -0.765 & 3.96 \\
\hline 0.1 & 84.32 & -1.85 & 5.12 \\
\hline 0.2 & 83.98 & -0.99 & 6.02 \\
\hline 0.3 & 84.23 & -1.501 & 6.67 \\
\hline 0.4 & 83.62 & -1.154 & 5.54 \\
\hline 0.5 & 83.58 & -0.976 & 5.78 \\
\hline 0.8 & 85.09 & -1.453 & 4.55
\end{tabular}

3.6. The antimicrobial activity study.

Chitosan and its derivatives have a superior biological activity, such as its antimicrobial activity. Chitosan has cationic nature in an acidic medium. Due to the presence of -NH2 groups, it has great ability to make destabilization of the bacterial outer membrane penetrate the plasma membrane and kill the bacteria [62-64]. There are several mechanisms discuss with an illustration of how chitosan kills the microbial cell (bacteria and fungi). But the main back draw of chitosan antimicrobial that its effect on some microbes, such as Gram-positive bacteria more efficient than that for Gram-negative bacteria. Therefore, chitosan nanoparticles offer the best solution for that problem due to their nanostructure.

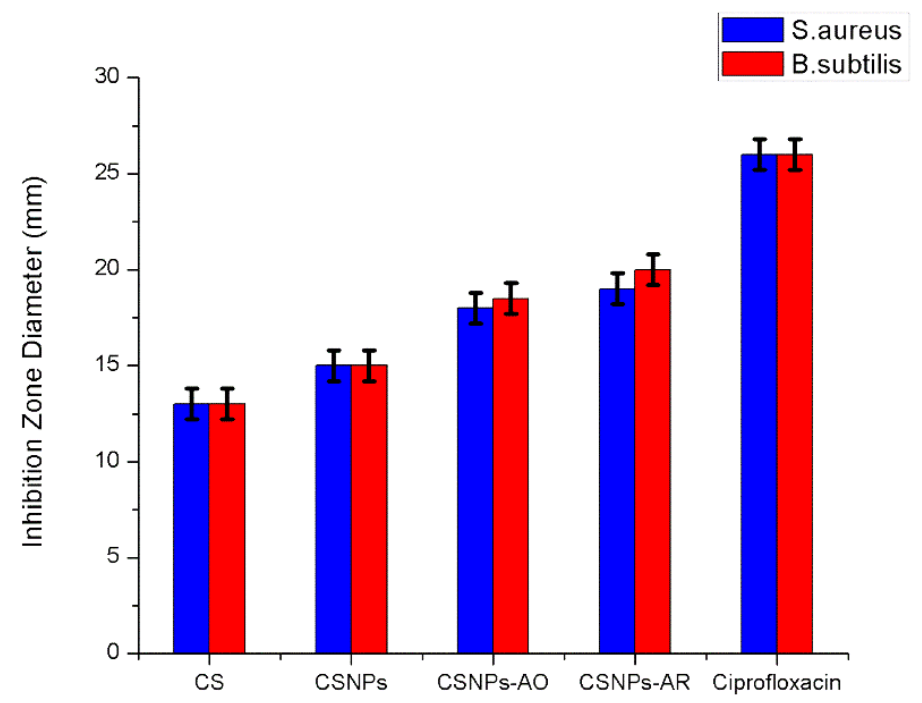

Figure 6. Antibacterial activity expressed in inhibition zone of cotton fabrics treated with chitosan, chitosan nanoparticles, CSNPs-AO dyed, and CSNPs-AR dyed samples against Gram-positive bacteria.

Figs. 6 and 7 shows the antibacterial activity of cotton fabric treated with chitosan, chitosan nanoparticles, CSNPs treated with dyed AO and AR against four bacterial species; two Gram-positive and two Gram-negative as mentioned in the experimental part. The antibacterial activity was evaluated via a disk diffusion method. Antimicrobial activity data represented in Fig. 6 and 7 explained why we used CSNPs for cotton fabric treatment instead of chitosan because it has higher antibacterial activity for Gram-positive and Gram-negative bacteria with chitosan itself. Chitosan has more antibacterial activity on Gram-positive than Gram-negative bacteria due to their difference in the surface wall. In addition, the increase in antimicrobial activity of two dyed cotton fabrics due to the presence of reactive groups $-\mathrm{N}=\mathrm{N}$ and sulphonic groups. 


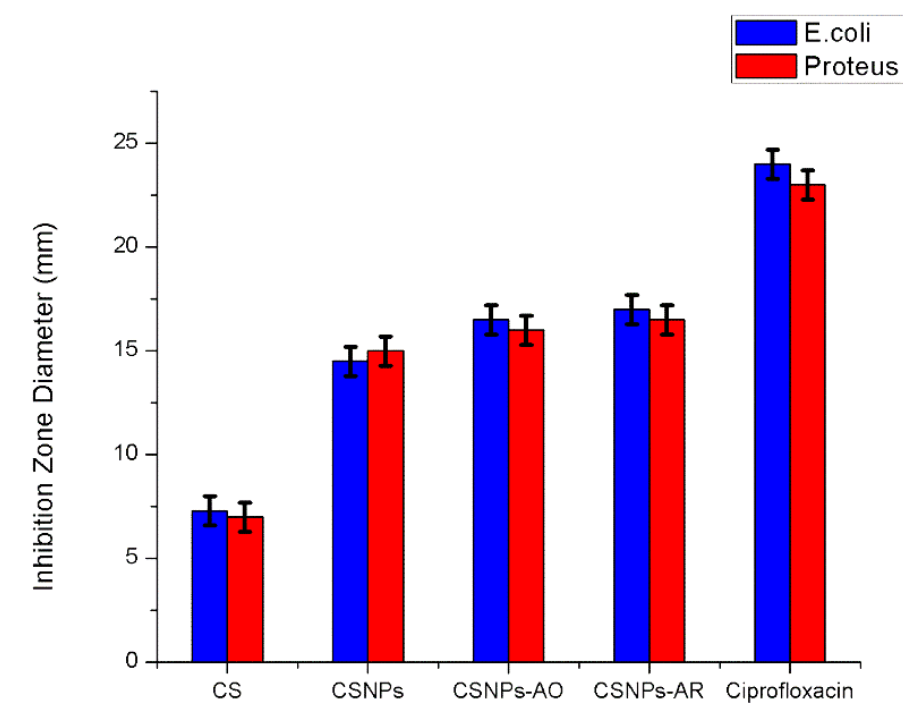

Figure 7. Antibacterial activity expressed in inhibition zone of cotton fabrics treated with chitosan, chitosan nanoparticles, CSNPs - AO dyed, and CSNPs - AR dyed samples against Gram-negative bacteria.

The antifungal activity of untreated, treated, and dyed cotton fabrics against Aspergillus niger and Candida with ciprofloxacin as a standard antibiotic are presented in Fig. 8.

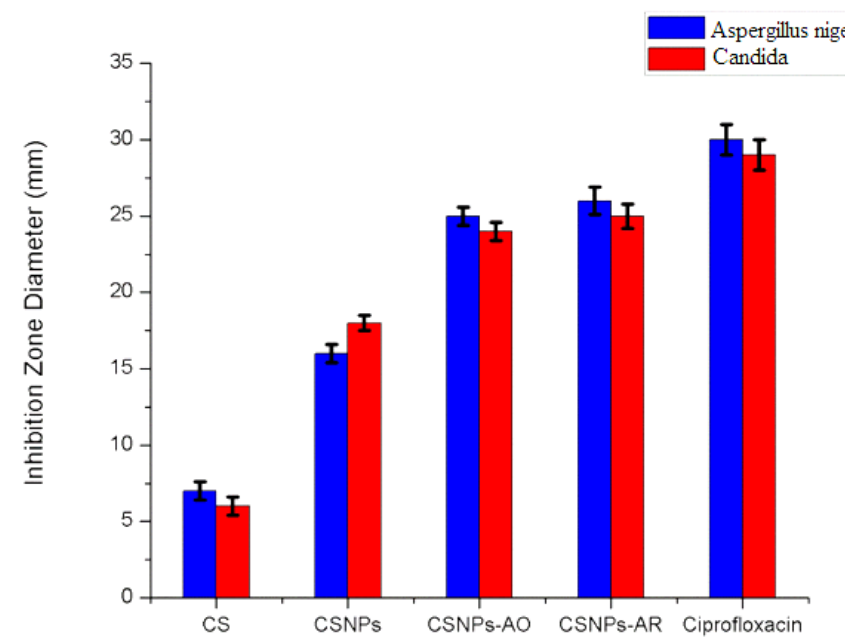

Figure 8. Antifungal activity expressed in inhibition zone of cotton fabrics treated with chitosan, chitosan nanoparticles, CSNPs - AO dyed, and CSNPs - AR dyed samples against Aspergillus niger and Candida.

Chitosan shows the lowest antifungal activity, whereas chitosan nanoparticles show higher results due to nanostructure more its penetrating power of fungi, as shown in Fig. 8. Also, the higher values of antifungal data of two dyed cotton fabrics due to the presence of reactive groups in their dye moiety

\section{Conclusions}

The improvement of cotton fabrics with acid dye has been made by finishing these fabrics with chitosan nanoparticles (CSNPs). CSNPs has been prepared from chitosan and tripolyphosphate via the ionotropic gelation method. CSNPs are characterized by TEM imaging and FT-IR spectroscopy. The dyeability and antimicrobial activity of cotton fabrics with $\mathrm{AR}$ and $\mathrm{AO}$ acid dyes were investigated after treatment with different concentrations of CSNPs. The pad-dry-cure method was used for cotton fabric treatment with different concentrations of safe biopolymer chitosan nanoparticles. Chitosan nanoparticles treatment was improved and enhanced the dyeability of cotton fabrics with AO and AR acid dyes due to 
chitosan nanoparticles could create new cationic charges from amino groups protonation on the cellulosic cotton fabrics surfaces. In addition, cotton fabrics' physicochemical and mechanical properties have been improved due to the high power penetration of nanoparticles and physical crosslinking within cotton fabrics (presence of $\mathrm{OH}$ and $\mathrm{NH}_{2}$ groups in CSNPS moiety). The optimum concentration of chitosan was $0.2 \mathrm{wt} \%$ for both dyeability and antibacterial activity improvement. Finally, chitosan nanoparticles impart these dyed cotton fabrics and antimicrobial activity towards Gram-positive, Gram-negative bacteria and fungi.

\section{Funding}

This research received no external funding.

\section{Acknowledgments}

This research has no acknowledgment.

\section{Conflicts of Interest}

The authors declare no conflict of interest.

\section{References}

1. Ibrahim, H.; Emam, E.A.M.; Tawfik, T.M.; El-Aref, A.T. Preparation of cotton gauze coated with carboxymethyl chitosan and its utilization for water filtration. Journal of Textile and Apparel, Technology and Management 2019, 11.

2. Aysha, T.; El-Sedik, M.; El Megied, S.A.; Ibrahim, H.; Youssef, Y.; Hrdina, R. Synthesis, spectral study and application of solid state fluorescent reactive disperse dyes and their antibacterial activity. Arabian Journal of Chemistry 2019, 12, 225-235, https://doi.org/10.1016/j.arabjc.2016.08.002.

3. Eid, B.M.; El-Sayed, G.M.; Ibrahim, H.M.; Habib, N.H. Durable Antibacterial Functionality of Cotton/Polyester Blended Fabrics Using Antibiotic/MONPs Composite. Fibers and Polymers 2019, 20, 2297-2309, https://doi.org/10.1007/s12221-019-9393-y.

4. Mohamed, F.A.; Ibrahim, H.M.; Aly, A.A.; El-Alfy, E.A. Improvement of dyeability and antibacterial properties of gelatin treated cotton fabrics with synthesized reactive dye. Bioscience Research 2018, 15, 4403-4408.

5. Mohamed, F.A.; Abd El-Megied, S.A.; Bashandy, M.S.; Ibrahim, H.M. Synthesis, application and antibacterial activity of new reactive dyes based on thiazole moiety. Pigment and Resin Technology 2018, 47, 246-254, https://doi.org/10.1108/PRT-12-2016-0117.

6. Ibrahim, H.M.; Farid, O.A.; Samir, A.; Mosaad, R.M. Preparation of chitosan antioxidant nanoparticles as drug delivery system for enhancing of anti-cancer drug. In: Key Engineering Materials. KEM, Volume 759, 2018; pp 92-97, https://doi.org/10.4028/www.scientific.net/KEM.759.92.

7. Mohamed, F.A.; Ibrahim, H.M.; Reda, M.M. Eco friendly dyeing of wool and cotton fabrics with reactive dyes (bifunctional) and its antibacterial activity. Der Pharma Chemica 2016, 8, 159-167.

8. Mohamed, F.A.; Ibrahim, H.M.; El-Kharadly, E.A.; El-Alfy, E.A. Improving dye ability and antimicrobial properties of cotton fabric. Journal of Applied Pharmaceutical Science 2016, 6, 119-123, https://doi.org/10.7324/JAPS.2016.60218.

9. Ibrahim, H.; El- Zairy, E.M.R.; Emam, E.A.M.; Adel, E. Combined antimicrobial finishing dyeing properties of cotton, polyester fabrics and their blends with acid and disperse dyes. Egyptian Journal of Chemistry 2019, 62, 965-976, https://doi.org/10.21608/EJCHEM.2018.6358.1535.

10. Farouk, R.; Youssef, Y.A.; Mousa, A.A.; Ibrahim, H.M. Simultaneous dyeing and antibacterial finishing of nylon 6 fabric using reactive cationic dyes. World Applied Sciences Journal 2013, 26, 1280-1287.

11. Eid, B.M.; El-Sayed, G.M.; Ibrahim, H.M.; Habib, N.H. Durable Antibacterial Functionality of Cotton/Polyester Blended Fabrics Using Antibiotic/MONPs Composite. Fibers Polym. 2019, 20, 2297-2309, https://doi.org/10.1007/s12221-019-9393-y.

12. Ibrahim, H.M.; Zaghloul, S.; Hashem, M.; El-Shafei, A. A green approach to improve the antibacterial properties of celluloseF2020, based fabrics using Moringa oleifera extract in presence of silver nanoparticles. Cellulose 2020, https://doi.org/10.1007/s10570-020-03518-7.

13. Dastjerdi, R.; Montazer, M. A review on the application of inorganic nano-structured materials in the modification of textiles: focus on antimicrobial properties. Colloids and Surfaces B: Biointerfaces 2010, 79, 5-18, https://doi.org/10.1016/j.colsurfb.2010.03.029. 
14. Ibrahim, H.M.; Aly, A.A.; Taha, G.M.; El-Alfy, E.A. Production of antibacterial cotton fabrics via green treatment with non-toxic natural biopolymer gelatin. Egyptian Journal of Chemistry 2020, 63, 655-696, https://doi.org/10.21608/ejchem.2019.16972.2040.

15. Ibrahim, N.A.; Eid, B.M.; Youssef, M.A.; Ibrahim, H.M.; Ameen, H.A.; Salah, A.M. Multifunctional finishing of cellulosic/polyester blended fabrics. Carbohydrate Polymers 2013, 97, 783-793, https://doi.org/10.1016/j.carbpol.2013.05.063.

16. Ibrahim, H.M.; Dakrory, A.; Klingner, A.; El-Masry, A.M.A. Carboxymethyl chitosan electrospun nanofibers: Preparation and its antibacterial activity. Journal of Textile and Apparel, Technology and Management 2015, 9.

17. Seyam, A.F.M.; Hudson, S.M.; Ibrahim, H.M.; Waly, A.I.; Abou-Zeid, N.Y. Healing performance of wound dressing from cyanoethyl chitosan electrospun fibres. Indian Journal of Fibre and Textile Research 2012, 37, 205-210.

18. Nawalakhe, R.G.; Hudso, S.M.; Seyam, A.M.; Waly, A.I.; Abou-Zeid, N.Y.; Ibrahim, H.M. Development of electrospun iminochitosan for improved wound healing application. Journal of Engineered Fibers and Fabrics 2012, 7, 47-55, https://doi.org/10.1177/155892501200700208.

19. Rinaudo, M. Chitin and chitosan: Properties and applications. Progress in Polymer Science 2006, 31, 603632, https://doi.org/10.1016/j.progpolymsci.2006.06.001.

20. Alves, N.M.; Mano, J.F. Chitosan derivatives obtained by chemical modifications for biomedical and environmental applications. International Journal of Biological Macromolecules 2008, 43, 401-414, https://doi.org/10.1016/j.ijbiomac.2008.09.007.

21. Zhao, Y.; Chen, P. Natural Products with Health Benefits from Marine Biological Resources. Current Organic Chemistry 2014, 18, 777-792, https://doi.org/10.2174/138527281807140515132853.

22. Duttagupta, D.S.; Jadhav, V.M.; Kadam, V.J. Chitosan: A Propitious Biopolymer for Drug Delivery. Current Drug Delivery 2015, 12, 369-381, https://doi.org/10.2174/1567201812666150310151657.

23. Thanou, M.; Verhoef, J.C.; Junginger, H.E. Oral drug absorption enhancement by chitosan and its derivatives. Advanced Drug Delivery Reviews 2001, 52, 117-126, https://doi.org/10.1016/S0169409X(01)00231-9.

24. Ibrahim, H.M.; El-Zairy, E.M.R. Carboxymethylchitosan nanofibers containing silver nanoparticles: Preparation, Characterization and Antibacterial activity. Journal of Applied Pharmaceutical Science 2016, 6, 43-48, https://doi.org/10.7324/JAPS.2016.60706.

25. Ibrahim, H.M.; Mostafa, M.; Kandile, N.G. Potential use of N-carboxyethylchitosan in biomedical applications: Preparation, characterization, biological properties. International Journal of Biological Macromolecules 2020, 149, 664-671, https://doi.org/10.1016/j.ijbiomac.2020.01.299.

26. Ibrahim, H.M.; Reda, M.M.; Klingner, A. Preparation and characterization of green carboxymethylchitosan (CMCS) - Polyvinyl alcohol (PVA) electrospun nanofibers containing gold nanoparticles (AuNPs) and its potential use as biomaterials. Int. J. Biol. Macromol. 2020, 151, 821-829, https://doi.org/10.1016/j.ijbiomac.2020.02.174.

27. El-Alfy, E.A.; El-Bisi, M.K.; Taha, G.M.; Ibrahim, H.M. Preparation of biocompatible chitosan nanoparticles loaded by tetracycline, gentamycin and ciprofloxacin as novel drug delivery system for improvement the antibacterial properties of cellulose based fabrics. International Journal of Biological Macromolecules 2020, 161, 1247-1260, https://doi.org/10.1016/j.ijbiomac.2020.06.118.

28. Ibrahim, H.M.; Klingner, A. A review on electrospun polymeric nanofibers: Production parameters and potential applications. Polymer Testing 2020, 90, https://doi.org/10.1016/j.polymertesting.2020.106647.

29. Li, H.-P.; Qin, L.; Wang, Z.-D.; Li, S. Synthesis and characterization of ramose tetralactosyl-lysyl-chitosan5-fluorouracil and its in vitro release. Research on Chemical Intermediates 2012, 38, 1421-1429, https://doi.org/10.1007/s11164-011-0473-X.

30. Gupta, N.K.; Tomar, P.; Sharma, V.; Dixit, V.K. Development and characterization of chitosan coated poly( $\varepsilon$-caprolactone) nanoparticulate system for effective immunization against influenza. Vaccine 2011, 29, 9026-9037, https://doi.org/10.1016/j.vaccine.2011.09.033.

31. Borges, O.; Tavares, J.; de Sousa, A.; Borchard, G.; Junginger, H.E.; Cordeiro-da-Silva, A. Evaluation of the immune response following a short oral vaccination schedule with hepatitis B antigen encapsulated into alginate-coated chitosan nanoparticles. European Journal of Pharmaceutical Sciences 2007, 32, 278-290, https://doi.org/10.1016/j.ejps.2007.08.005.

32. Gan, Q.; Wang, T.; Cochrane, C.; McCarron, P. Modulation of surface charge, particle size and morphological properties of chitosan-TPP nanoparticles intended for gene delivery. Colloids and Surfaces B: Biointerfaces 2005, 44, 65-73, https://doi.org/10.1016/j.colsurfb.2005.06.001.

33. Ramyadevi, J.; Jeyasubramanian, K.; Marikani, A.; Rajakumar, G.; Rahuman, A.A. Synthesis and antimicrobial activity of copper nanoparticles. Materials Letters 2012, 71, 114-116, https://doi.org/10.1016/j.matlet.2011.12.055.

34. Stanić, V.; Dimitrijević, S.; Antić-Stanković, J.; Mitrić, M.; Jokić, B.; Plećaš, I.B.; Raičević, S. Synthesis, characterization and antimicrobial activity of copper and zinc-doped hydroxyapatite nanopowders. Applied Surface Science 2010, 256, 6083-6089, https://doi.org/10.1016/j.apsusc.2010.03.124. 
35. Martinez-Gutierrez, F.; Olive, P.L.; Banuelos, A.; Orrantia, E.; Nino, N.; Sanchez, E.M.; Ruiz, F.; Bach, H.; Av-Gay, Y. Synthesis, characterization, and evaluation of antimicrobial and cytotoxic effect of silver and titanium nanoparticles. Nanomedicine: Nanotechnology, Biology and Medicine 2010, 6, 681-688, https://doi.org/10.1016/j.nano.2010.02.001.

36. Lellouche, J.; Kahana, E.; Elias, S.; Gedanken, A.; Banin, E. Antibiofilm activity of nanosized magnesium fluoride. Biomaterials 2009, 30, 5969-5978, https://doi.org/10.1016/j.biomaterials.2009.07.037.

37. Abdel Sayed, N.I.; El Badry, K.; Abdel Mohsen, H.M. Conductimetric studies of charge transfer complexes of p-Chloranil with some alicyclic amines in polar media. Journal of the Chinese Chemical Society 2003, 50, 193-199.

38. Farag, S.; Ibrahim, H.M.; Asker, M.S.; Amr, A.; El-Shafaee, A. Impregnation of silver nanoparticles into bacterial cellulose: Green synthesis and cytotoxicity. International Journal of ChemTech Research 2015, 8, 651-661.

39. Qi, L.; Xu, Z.; Jiang, X.; Hu, C.; Zou, X. Preparation and antibacterial activity of chitosan nanoparticles. Carbohydrate Research 2004, 339, 2693-2700, https://doi.org/10.1016/j.carres.2004.09.007.

40. El-Bisi, M.K.; Ibrahim, H.M.; Rabie, A.M.; Elnagar, K.; Taha, G.M.; El-Alfy, E.A. Super hydrophobic cotton fabrics via green techniques. Der Pharma Chemica 2016, 8, 57-69.

41. Ibrahim, H.M.; El-Bisi, M.K.; Taha, G.M.; El-Alfy, E.A. Chitosan nanoparticles loaded antibiotics as drug delivery biomaterial. Journal of Applied Pharmaceutical Science 2015, 5, 85-90, https://doi.org/10.7324/JAPS.2015.501015.

42. Tiyaboonchai, W. Chitosan nanoparticles: a promising system for drug delivery. Naresuan University Journal: Science and Technology (NUJST) 2013, 11, 51-66, https://doi.org/10.1248/cpb.58.1423.

43. Elgadir, M.A.; Uddin, M.S.; Ferdosh, S.; Adam, A.; Chowdhury, A.J.K.; Sarker, M.Z.I. Impact of chitosan composites and chitosan nanoparticle composites on various drug delivery systems: A review. Journal of Food and Drug Analysis 2015, 23, 619-629, https://doi.org/10.1016/j.jfda.2014.10.008.

44. Piras, A.M.; Maisetta, G.; Sandreschi, S.; Esin, S.; Gazzarri, M.; Batoni, G.; Chiellini, F. Preparation, physical-chemical and biological characterization of chitosan nanoparticles loaded with lysozyme. International Journal of Biological Macromolecules 2014, 67, 124-131, https://doi.org/10.1016/j.ijbiomac.2014.03.016.

45. Ibrahim, H.M.; Saad, M.M.; Aly, N.M. Preparation of single layer nonwoven fabric treated with chitosan nanoparticles and its utilization in gas filtration. International Journal of ChemTech Research 2016, 9, 1-16.

46. Shi, L.E.S.; Chen, M.; Xinf, L.Y.; Guo, X.F.; Zhao, L.M. Chitosan nanoparticles as drug delivery carriers for biomedical engineering. Journal of the Chemical Society of Pakistan 2011, 33, 929-934.

47. Agnihotri, S.A.; Mallikarjuna, N.N.; Aminabhavi, T.M. Recent advances on chitosan-based micro- and nanoparticles in drug delivery. Journal of Controlled Release 2004, 100, 5-28, https://doi.org/10.1016/j.jconrel.2004.08.010.

48. Mosaad, R.M.; Samir, A.; Ibrahim, H.M. Median lethal dose (LD50) and cytotoxicity of Adriamycin in female albino mice. Journal of Applied Pharmaceutical Science 2017, 7, 77-80, https://doi.org/10.7324/JAPS.2017.70312.

49. Farag, S.; Asker, M.M.S.; Mahmoud, M.G.; Ibrahim, H.; Amr, A. Comparative study for bacterial cellulose production Using Egyptian Achromobacter sp. Research Journal of Pharmaceutical, Biological and Chemical Sciences 2016, 7, 954-969.

50. Ibrahim, N.A.; Kadry, G.A.; Eid, B.M.; Ibrahim, H.M. Enhanced antibacterial properties of polyester and polyacrylonitrile fabrics using Ag-Np dispersion/microwave treatment. AATCC Journal of Research 2014, 1, 13-19, https://doi.org/10.14504/ajr.1.2.2.

51. Farag, S.; Ibrahim, H.M.; Amr, A.; Asker, M.S.; El-Shafai, A. Preparation and characterization of ion exchanger based on bacterial cellulose for heavy metal cation removal. Egyptian Journal of Chemistry 2019, 62, 457-466, https://doi.org/10.21608/ejchem.2019.12622.1787.

52. Wei, W.; Zhou, Y.-H.; Chang, H.-J.; Yeh, J.-T. Antibacterial and Miscibility Properties of Chitosan/Collagen Blends. Journal of Macromolecular Science, Part B 2015, 54, 143-158, https://doi.org/10.1080/00222348.2014.987097.

53. Ibrahim, H.; Dakrory, A.; Klingner, A.; El-Masry, A. Carboxymethyl Chitosan Electrospun Nanofibers: Preparation and its Antibacterial Activity. Journal of Textile \& Apparel Technology \& Management (JTATM) 2015, 9.

54. Abdelgawad, A.M.; Hudson, S.M. Chitosan nanoparticles: Polyphosphates crosslinking and protein delivery properties. International Journal of Biological Macromolecules 2019, 136, 133-142, https://doi.org/10.1016/j.ijbiomac.2019.06.062.

55. Hasanzadeh Kafshgari, M.; Khorram, M.; Khodadoost, M.; Khavari, S. Reinforcement of chitosan nanoparticles obtained by an ionic crosslinking process. Iranian Polymer Journal (english) 2011, 20, 445456.

56. Naskar, S.; Kuotsu, K.; Sharma, S. Chitosan-based nanoparticles as drug delivery systems: a review on two decades of research. Journal of Drug Targeting 2019, 27, 379-393, https://doi.org/10.1080/1061186X.2018.1512112. 
57. Rayment, P.; Butler, M.F. Investigation of ionically crosslinked chitosan and chitosan-bovine serum albumin beads for novel gastrointestinal functionality. Journal of Applied Polymer Science 2008, 108, 28762885.

58. Kolesov, S.V.; Gurina, M.S.; Mudarisova, R.K. On the Stability of Aqueous Nanodispersions of Polyelectrolyte Complexes Based on Chitosan and N-Succinyl-Chitosan. Polymer Science, Series A 2019, 61, 253-259, https://doi.org/10.1134/S0965545X19030076.

59. Wang, Q.; Dong, Z.; Du, Y.; Kennedy, J.F. Controlled release of ciprofloxacin hydrochloride from chitosan/polyethylene glycol blend films. Carbohydrate Polymers 2007, 69, 336-343, https://doi.org/10.1016/j.carbpol.2006.10.014.

60. Xu, Y.; Du, Y. Effect of molecular structure of chitosan on protein delivery properties of chitosan nanoparticles. International Journal of Pharmaceutics 2003, 250, 215-226, https://doi.org/10.1016/S03785173(02)00548-3.

61. Tian, M.; Qu, L.; Zhang, X.; Zhang, K.; Zhu, S.; Guo, X.; Han, G.; Tang, X.; Sun, Y. Enhanced mechanical and thermal properties of regenerated cellulose/graphene composite fibers. Carbohydrate Polymers 2014, 111, 456-462, https://doi.org/10.1016/j.carbpol.2014.05.016.

62. Tang, H.; Zhang, P.; Kieft, T.L.; Ryan, S.J.; Baker, S.M.; Wiesmann, W.P.; Rogelj, S. Antibacterial action of a novel functionalized chitosan-arginine against Gram-negative bacteria. Acta Biomaterialia 2010, 6 , 2562-2571, https://doi.org/10.1016/j.actbio.2010.01.002.

63. Sahariah, P.; Másson, M. Antimicrobial Chitosan and Chitosan Derivatives: A Review of the StructureActivity Relationship. $\quad$ Biomacromolecules $\quad 2017, \quad$ 18, 3846-3868, https://doi.org/10.1021/acs.biomac.7b01058.

64. Ma, Z.; Garrido-Maestu, A.; Jeong, K.C. Application, mode of action, and in vivo activity of chitosan and its micro- and nanoparticles as antimicrobial agents: A review. Carbohydrate Polymers 2017, 176, 257-265, https://doi.org/10.1016/j.carbpol.2017.08.082. 